\title{
Association of tobacco control policies with cigarette smoking among school youth aged 13-15 years in the Philippines, 2000-2015
}

\begin{abstract}
René A. Arrazola', Lauren M. Dutra², Evelyn Twentyman', Andrew B. Seidenberg³, Rizalina Hemendez-Gonzales', Indu B.
\end{abstract} Ahluwalia $^{1}$

\begin{abstract}
INTRODuction In 2003, the Philippines implemented legislation that prohibited the sale of tobacco products to youth, placed text warning labels on tobacco products, and prohibited tobacco smoking in public places. This study assessed if this legislation was associated with reduced cigarette smoking among youth.

METHODS Data came from the 2000-2015 Philippines Global Youth Tobacco Survey (GYTS), a nationally representative, cross-sectional survey of students aged 1315 years. GYTS data were used to determine associations between tobacco control legislation and current, past 30-day, current cigarette smoking (CCS). Logistic regression models were adjusted for age, sex, current other tobacco product use (COTPU), and price per cigarette stick (PPCS).

RESULTS In the unadjusted model, the 2003 legislation was not associated with CCS $(\mathrm{OR}=0.77$; 95\% CI: 0.54-1.10). After adjusting for covariates, it was negatively associated $(\mathrm{AOR}=0.65 ; 95 \% \mathrm{CI}$ : $0.53-0.80)$. Being 15 years old $(\mathrm{OR}=1.31 ; 95 \%$ CI: $1.08-1.58)$, male (OR=2.54; 95\% CI: 2.17-2.98), and COTPU (OR=4.12; 95\% CI: 3.47-4.91) were positively associated with CCS in unadjusted models. In adjusted models, being 14 years old ( $\mathrm{AOR}=1.29$; 95\% CI: 1.08-1.53), 15 years old $(\mathrm{AOR}=1.55 ; 95 \% \mathrm{CI}: 1.31-1.84)$, male $(\mathrm{AOR}=2.49 ; 95 \% \mathrm{CI}: 2.13-2.91)$, and COTPU (AOR=3.96; 95\% CI: 3.32-4.73), were associated with CCS. PPCS was not associated with CCS in either the unadjusted ( $\mathrm{OR}=1.32$; 95\% CI: 0.82-2.11) or adjusted (AOR=1.32; 95\% CI: 0.79-2.18) models.

concLusions After adjusting for covariates, the 2003 tobacco control legislation was associated with lower current cigarette smoking, but price per cigarette stick was not.
\end{abstract}

\section{AFFILIATION}

1 Office on Smoking and Health, National Center for Chronic Disease Prevention and Health Promotion, Centers for Disease Control and Prevention, Atlanta, United States 2 Center for Health Policy Science and Tobacco Control Research, RTI International, Berkeley, United States

3 Department of Health Behavior, Gillings School of Global Public Health, University of North Carolina at Chapel Hill, Chapel Hill, United States

4 Tobacco Advocacy Group, Philippine Pediatric Society,

Quezon, Philippines

CORRESPONDENCE TO

René A. Arrazola. Office on

Smoking and Health, National

Center for Chronic Disease

Prevention and Health Promotion,

Centers for Disease Control and

Prevention, Atlanta, GA, United

States. E-mail: fdy9@cdc.gov

KEYWORDS

GYTS, school youth, tobacco control policies, the Philippines

Received: 20 March 2020

Revised: 8 May 2020

Accepted: 14 May 2020

\section{INTRODUCTION}

Tobacco use contributes to more than 8 million deaths globally each year ${ }^{1}$, including more than 110000 deaths each year in the Philippines ${ }^{1,2}$. Smoked tobacco products, such as cigarettes, are the most common form of tobacco used worldwide ${ }^{3}$ and most people who smoke tobacco begin smoking during adolescence ${ }^{4}$. Smoking during adolescence is known to cause health problems, such as increased number and severity of respiratory illnesses, and continued smoking across the life course also causes numerous cancers and cardiovascular disease ${ }^{5}$. 
From 2000 to 2015, current cigarette smoking among youth declined in the Philippines ${ }^{6}$. However, more than 1 in 10 Filipino youth still currently smoked cigarettes in $2015^{6}$. Thus, for the Philippines to achieve its goal of reducing youth's current tobacco use by $2 \%$ per year ${ }^{6}$, preventing tobacco use among youth remains a critical strategy ${ }^{4}$.

To combat the youth tobacco epidemic, the Philippines implemented tobacco control legislation (Republic Act No. 9211) in 2003 that included prohibiting the sale of tobacco products to those aged $<18$ years, placing text warning labels on tobacco products, and prohibiting tobacco smoking in public places ${ }^{7}$. The law allowed for designated smoking areas and did not prohibit the sale of single cigarette sticks ${ }^{7,8}$. These exceptions could diminish the public health effects of the legislation because completely eliminating smoking indoors is the only way to fully protect people from involuntary exposure to secondhand smoke ${ }^{9}$, and the sale of single cigarette sticks makes cigarettes easier to obtain for minors ${ }^{10}$.

In 2005, the Philippines ratified the World Health Organization's (WHO) Framework Convention on Tobacco Control (FCTC), the first international public health treaty developed in response to the global tobacco epidemic ${ }^{10}$. Since 2005 , government agencies and local government units have issued policies and ordinances ${ }^{8}$, including the Republic Act No. 9211, and taken implementation steps to be compliant with the FCTC and WHO's MPOWER measures ${ }^{11}$. Furthermore, in 2012, the Philippines passed Republic Act No. 10351 to reform the excise tax and tax structure on tobacco products, which increased the tax on cigarettes by more than $300 \%$ in its first year (2013) of implementation, culminating in an increase of as high as $1000 \%$ by $2018^{12}$.

Although there have been enhancements to smoke-free environment legislation since 2015, the law continues to allow smoking indoors in some settings; therefore, these enhancements are still not compliant with FCTC's 100\% smokefree recommendation, as described in Article $8^{8,10}$. Furthermore, in 2019, the Philippines passed tobacco control legislation that continued to tax cigarettes progressively; however, this legislation did not include a measure to prohibit the sale of single sticks ${ }^{13}$, thereby continuing to allow access to lower priced cigarettes.

To date, no study has assessed the impact of tobacco control policies adopted in the Philippines. To address this gap in the scientific literature, this study aims to determine if tobacco control policies adopted by the Philippines were associated with a reduction in current cigarette smoking among youth aged 13-15 years who attend school.

\section{METHODS}

\section{Data source}

We used data from the five rounds $(2000,2004,2007$, 2011, and 2015) of the Philippines's Global Youth Tobacco Survey (GYTS). The GYTS is a nationally representative, school-based, paper-and-pencil, cross-sectional survey of students in school grades associated with ages $13-15$ years $^{14}$. Overall response rates and sample sizes were: $79.5 \%(n=5582)$ in 2000 , $84.8 \%(n=4033)$ in $2004,80.9 \%(n=3278)$ in 2007 , $84.1 \%(n=3708)$ in 2011 , and $82.7 \%(n=5885)$ in 2015. Respondents with missing values on any of the variables of interest were excluded from the analytic models, resulting in an overall analytical sample size of 20366 out of 22486 students (90.6\%).

\section{Measures}

\section{Dependent variable}

The following question was used to define current cigarette smoking: 'During the past 30 days, on how many days did you smoke cigarettes?'. The current cigarette smoking indicator was dichotomized (' 0 ' for those reporting 0 days in the past 30 days, and ' 1 ' for those reporting $\geq 1$ day in the past 30 days).

\section{Independent variables}

Correlates of current cigarette smoking were included in the adjusted models, including sex (male and female), age (13, 14, or 15 years), current use of other tobacco products (e.g. smokeless tobacco, cigars, hookah), and average price per cigarette stick during each of the years for which data were collected.

Although similar tobacco products were assessed over time for current use of other tobacco products, the wording of the questions varied. Therefore, the following questions were for the operational definition of current use of other tobacco products for each year:

1. In 2000 and 2004 , the question used to define 
current use of other tobacco product was: 'During the past 30 days (one month), have you ever used any form of tobacco products other than cigarettes (e.g. chewing tobacco, snuff, dip, cigars, cigarillos, little cigars, pipes)?'. Responses were dichotomized as current users of other tobacco products ( 0 for those reporting 'No', and 1 for those reporting 'Yes').

2. In 2007 and 2011, the questions used to define current use of other tobacco products were: 'During the past 30 days (one month), have you ever used any form of smoked-tobacco products other than cigarettes (e.g. cigars, pipes)?' and 'During the past 30 days (one month), have you ever used any form of smokeless-tobacco products other than cigarettes (e.g. chewing tobacco)?'. Responses were dichotomized as current users of other tobacco products ( 0 for those reporting 'No' to both questions, and 1 for those reporting 'Yes' to at least one of the two questions).

3 . In 2015 , the questions used to define current use of other tobacco were: 'During the past 30 days, did you use any form of smoked tobacco products other than cigarettes (such as cigars, waterpipes, pipes, shisha, bidis)?' and 'During the past 30 days, did you use any form of smokeless tobacco products (such as snuff, chewing tobacco, dip, betel quid with tobacco, gutka)?'. Responses were dichotomized as current users of other tobacco products ( 0 for those reporting 'No' to both questions, and 1 for those reporting 'Yes' to at least one of the two questions).

Republic Act No. 9211 was passed in 2003 and included three key tobacco control components: 1) minimum legal sales age of 18 years; 2 ) text warnings on cigarette packs; and 3) smoke-free public places. In our model, this policy change was coded as ' 1 ' starting in 2004; otherwise, it was coded as ' 0 ' in 2000. To control for increase in taxes resulting from passage of Republic Act No. 10351, the average price per cigarette stick in the Philippines was obtained for each year corresponding to GYTS data from Euromonitor, a market research provider (www.euromonitor.com). To adjust for inflation, the average price per cigarette stick was converted into 2015 Philipine Pesos (about 46 PHP to 1 US\$) by using the International Monetary Fund's
International Financial Statistics, 2017 M08. The average price per cigarette stick includes taxes, and the price data for 2015 incorporate the increase in price stemming from the passage of Republic Act No. 10351.

\section{Statistical analysis}

Multivariable logistic regression analysis was used to assess the association between current cigarette smoking among youth aged 13-15 years who attend school and Filipino tobacco control policies. Bivariable models were adjusted for survey year only, and the full model was adjusted for all covariates except year. Year was not included in the full model as it was found to be collinear (variance inflation factor [VIF] = 3.02); and without year in the full model, all other VIFs were less than 1.10.

For trend analysis of current use of other tobacco products from 2000 to 2015 , orthogonal polynomials were used with logistic regression analysis to simultaneously assess for linear and nonlinear trends, controlling for age and sex. A test for linear trend was considered significant if an overall statistically significant decrease or increase occurred during the study period; a significant nonlinear trend indicates the rate of change changed across the study period.

All analyses were conducted by using SASCallable SUDAAN version 11.0.1 (RTI International, Research Triangle Park, NG) to account for the complex survey sampling and weights of the GYTS. Results were considered to be statistically significant for $\mathrm{p}<0.05$.

\section{RESULTS}

Tobacco control legislation and current cigarette smoking

In models that just adjusted for year, Republic Act No. 9211 was not significantly associated with current cigarette smoking ( $\mathrm{OR}=0.77$; 95\% CI: $0.54-1.10)$ (Table 1); participants who were older (for those aged 15 years, $\mathrm{OR}=1.31 ; 95 \%$ CI: $1.08-1.58)$, male $(\mathrm{OR}=2.54 ; 95 \% \mathrm{CI}: 2.17-2.98)$, and currently used other tobacco products ( $\mathrm{OR}=4.12$; 95\% CI: 3.47-4.91) had higher odds ratio for current cigarette smoking.

In the model adjusted for age, sex, current use of other tobacco products, and price per cigarette stick, Republic Act No. 9211 was significantly associated 
Table 1. Factors associated with current cigarette smoking a among Filipino youth aged $13-15$ years who attended school in the Philippines, GYTS 2000-2015

\begin{tabular}{|c|c|c|}
\hline Factors & OR $\left(95^{\circ} \% \mathrm{CI}\right)^{b}$ & $\operatorname{AOR}\left(95^{\circ} \% \mathrm{CI}\right)^{\mathrm{c}}$ \\
\hline \multicolumn{3}{|l|}{ Age (years) } \\
\hline 13 & Ref. & Ref. \\
\hline 14 & $1.12(0.93-1.34)$ & $1.29(1.08-1.53)^{*}$ \\
\hline 15 & $1.31(1.08-1.58)^{*}$ & $1.55(1.31-1.84)^{*}$ \\
\hline \multicolumn{3}{|l|}{ Sex } \\
\hline Female & Ref. & Ref. \\
\hline Male & $2.54(2.17-2.98)^{*}$ & $2.49(2.13-2.91)^{*}$ \\
\hline \multicolumn{3}{|l|}{$\begin{array}{l}\text { Current use of other } \\
\text { tobacco products }^{d}\end{array}$} \\
\hline No & Ref. & Ref. \\
\hline Yes & $4.12(3.47-4.91)^{*}$ & $3.96(3.32-4.73)^{*}$ \\
\hline Price per cigarette stick & $1.32(0.82-2.11)$ & $1.32(0.79-2.18)$ \\
\hline \multicolumn{3}{|l|}{$\begin{array}{l}\text { Republic Act No. } 9211 \text { in } \\
\text { effect }\end{array}$} \\
\hline No & Ref. & Ref. \\
\hline Yes & $0.77(0.54-1.10)$ & $0.65(0.53-0.80)^{*}$ \\
\hline \multicolumn{3}{|c|}{$\begin{array}{l}\text { * Statistically significant at } p<0.05 \text {. Cl: confidence interval. a Current cigarette } \\
\text { smoking defined as smoking a cigarette on } \geq 1 \text { days in the past } 30 \text { days. b OR: } \\
\text { Unadjusted odds ratio, model included year. c AOR: adjusted odd ratio, full model } \\
\text { included all variables except year, as year was found to be collinear (variance inflation } \\
\text { factor }=3.02 \text { ). Without year in model, all variance inflation factors were less than } \\
1.10 \text {. d Use of other tobacco products was defined as smoking a tobacco product } \\
\text { other than cigarettes and/or using smokeless tobacco products on } \geq 1 \text { day in the past } \\
30 \text { days. e Cigarette price per stick was obtained from Euromonitor for the average } \\
\text { annual price per cigarette stick. All prices were adjusted to } 2015 \text { Philipine Pesos (about } \\
46 \text { PHP to } 1 \text { US } \$, 2015 \text { ) by using the International Monetary Fund's International } \\
\text { Financial Statistics, 2017 M08. }\end{array}$} \\
\hline
\end{tabular}

with lower odds of current cigarette smoking (AOR $=0.65$; 95\% CI: 0.53-0.80) (Table 1). After adjustment, participants who were older (aged 14 years, $\mathrm{AOR}=1.29 ; 95 \% \mathrm{CI}: 1.08-1.53$; aged 15 years, $\mathrm{AOR}=1.55$; 95\% CI: $1.31-1.84)$, male $(\mathrm{AOR}=2.49$; 95\% CI: 2.13-2.91), and currently used other tobacco products (AOR=3.96; 95\% CI: 3.32-4.73) had higher odds ratio for current cigarette smoking. Price per cigarette stick was not associated with current cigarette smoking in either model.

After converting all prices per cigarette stick to 2015 PHP, there was a decrease in the price per cigarette stick from 2.03 to 1.80 PHP, a relative decrease of $11.33 \%$ from 2000 to 2011 (Figure 1). After the implementation of the Republic Act No. 10351, there was an increase in the price per cigarette stick from 1.80 to 2.30 PHP, a relative increase of $27.78 \%$ from 2011 to 2015 . The Philippines had previously reported that there was a significant linear decrease in current cigarette smoking among students aged 13-15 years, from $18.22 \%$ in 2000 to $11.98 \%$ in $2015^{15}$, which is consistent with our findings. We also found that there was a significant linear decrease for current use of other tobacco products, from $11.09 \%$ in 2000 to $5.24 \%$ in 2015 .

Figure 1. Current cigarette smoking ${ }^{a, b}$ prevalence and current use of other tobacco products ${ }^{b, c}$ prevalence among Filipino youth aged 13-15 years who attended school, the Philippines Global Youth Tobacco Survey, 2000-2015; and average price per cigarette stick in Filipino pesos $(\mathrm{PhP})^{d}$

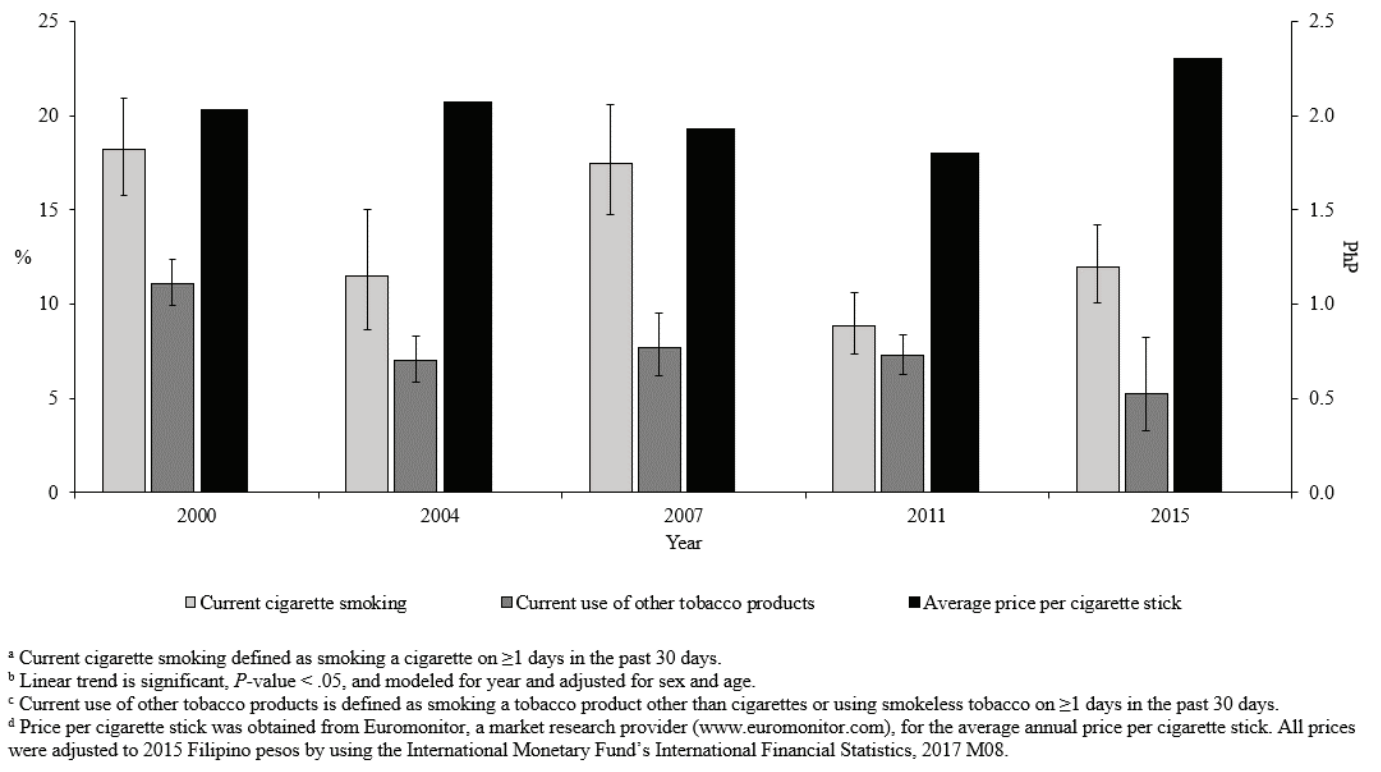




\section{DISCUSSION}

The Philippines had previously reported that there was a significant linear decrease in current cigarette smoking among students aged 13-15 years from the 2000 to 2015 rounds of the GYTS ${ }^{15}$. Our findings reveal that Republic Act 9211 was associated with the decrease in current cigarette smoking that occurred during that period. However, our empirical findings produced mixed results given that the change in price per cigarette stick was not associated with a change in current cigarette smoking.

Given previous research findings that youth are sensitive to cigarette prices, globally ${ }^{4,16-18}$, the finding that the average price per cigarette was not associated with youth current cigarette use was unexpected. However, this finding is likely due to the legal sales of single cigarette sticks in the Philippines during the assessed period. Further examination of the data revealed that the average price of a single cigarette stick increased from 1.80 PHP (approximately 0.04 US\$) in 2011 to 2.30 PHP (approximately 0.05 US\$) in 2015, which equates to an approximate increase of 0.50 PHP (0.01 US\$). The increase in taxes appears large in percentage terms, equating to more than $300 \%$ in its first year of implementation and culminating in an increase as high as $1000 \%$. However, the small change in average price at the unit level (single stick) might explain why this price change was not associated with lower odds of youth current cigarette use. Furthermore, the sale of single cigarette sticks is not prohibited in the Philippines ${ }^{8}$, and in $2015,81 \%$ of youth who currently smoked cigarettes reported purchasing single cigarette sticks ${ }^{6}$. The sale of single cigarette sticks makes cigarettes easier to obtain for minors ${ }^{10}$. FCTC calls for implementing tax policies and, where appropriate, price policies on tobacco products so as to reduce tobacco consumption (Article 6), as well as prohibiting the sale of cigarettes individually or in small packets, which makes such products more accessible to minors $(\text { Article 16) })^{10}$.

Since 2015, the Philippines has implemented additional policies and ordinances to be more compliant with FCTC, including expansion of prohibitions on tobacco advertisement, promotion and sponsorship (TAPS), implementation of pictorial health warnings, enhanced implementation of smoke-free environments, and continued implementation of progressive taxes on cigarettes ${ }^{8}$. However, the sale of single cigarette sticks is still not prohibited $^{8}$. The impact that the policies passed since 2015 could have on youth current cigarette smoking remains unknown. Future research should assess the effects that these new policies have on current cigarette smoking among Filipino youth.

\section{Limitations}

This study is subject to at least nine limitations. First, data are representative of only youth aged 13-15 years who attend school, which limits generalizability to all youth. Second, the data are cross-sectional; thus, causality cannot be inferred. Third, data are selfreported, which may result in misreporting of tobacco use behavior. Fourth, GYTS surveys in the Philippines assessed youth purchasing of single sticks in 2015 only, so we could not control for that variable in the model. Fifth, the GYTS surveys in the Philippines did not measure family income; thus, we could not control for this in our model. Sixth, the GYTS survey in the Philippines did not assessed the cigarette brand that youth usually smoked in 2015 , so we could not control for the average price for specific brands that youth usually smoked in the model. Seventh, there was no information on enforcement of Republic Act 9211 either at the local or national levels, which could affect youth cigarette smoking, going back to the start of the study period; thus, we could not control for this in our model. Eighth, some local government units may have introduced stronger smoke-free policies and ordinances than Republic Act 9211 but we could not control for the local smoke-free policies and ordinances in our model as a variable as the location where the data were collected is not available in the GYTS. Finally, the operational definition of current use of other tobacco products changed over time; however, sensitivity analyses showed that the removal of this variable did not change our overall findings.

\section{CONCLUSIONS}

After adjusting for covariates, the development and implementation of Republic Act No. 9211 was associated with a decrease in odds ratio of current cigarette smoking, whereas the price per cigarette stick was not associated with current cigarette smoking among Filipino youth aged 13-15 years. Although this 
study provides mixed evidence about current cigarette smoking and tobacco control legislation among Filipino youth aged 13-15 years who attend school, these findings could be explained by these policies not fully aligning with the evidence-based components of WHO's FCTC and MPOWER. Continued implementation and enforcement of comprehensive, evidence-based tobacco control policies that align with WHO's $\mathrm{FCTG}^{10}$ and MPOWER ${ }^{11}$, including prohibiting the sale of single cigarette sticks, could help to further reduce tobacco use among youth in the Philippines.

\section{REFERENCES}

1. University of Washington. Global Health Data Exchange. Seattle, WA: Institute for Health Metrics and Evaluation, University of Washington; 2017. http://ghdx.healthdata. org/gbd-results-tool. Accessed June 14, 2019.

2. American Cancer Society, Vital Strategies. The tobacco atlas: Philippines. https://tobaccoatlas.org/country/ philippines/. Accessed March 5, 2019.

3. Asma S, Mackay J, Song SY, Zhao L, Morton J, Palipudi KM, et al. The GATS Atlas. Atlanta, GA: CDC Foundation; 2015. http://gatsatlas.org/. Accessed March 6, 2019.

4. U.S. Department of Health and Human Services. Preventing Tobacco Use Among Youth and Young Adults: A Report of the Surgeon General. Atlanta, GA: U.S. Department of Health and Human Services, Centers for Disease Control and Prevention, National Center for Chronic Disease Prevention and Health Promotion, Office on Smoking and Health; 2012. https://www.ncbi.nlm.nih. gov/books/NBK99237/pdf/Bookshelf_NBK99237.pdf. Accessed March 6, 2019.

5. Schauer GL, Agaku IT, King BA, Malarcher AM. Health care provider advice for adolescent tobacco use: results from the 2011 National Youth Tobacco Survey. Pediatrics. 2014;134(3):446-455. doi:10.1542/peds.2014-0458

6. Republic of the Philippines, Department of Health. 2015 Global Youth Tobacco Survey (GYTS) Country Report (Philippines). https://www.doh.gov.ph/node/12500. Accessed March 20, 2019.

7. Republic of Philippines. Tobacco Regulation: Act of 2003, Republic Act No. 9211. https://www.who.int/ fctc/reporting/Philippines_annex3_packaging_and_ advertising2003.pdf. Accessed March 6, 2020.

8. Campaign for Tobacco-Free Kids. Tobacco Control Laws - Legislation by Country: Philippines. https://www. tobaccocontrollaws.org/legislation/country/philippines/ summary. Accessed June 1, 2019.

9. U.S. Department of Health and Human Services. The Health Consequences of Involuntary Exposure to Tobacco Smoke: A Report of the Surgeon General. Atlanta, GA: U.S. Department of Health and Human Services, Centers for Disease Control and Prevention, Coordinating Center for Health Promotion, National Center for Chronic Disease Prevention and Health Promotion, Office on Smoking and Health; 2006. https://www.ncbi.nlm.nih. gov/books/NBK44324/pdf/Bookshelf_NBK44324.pdf. Accessed December 12, 2019.

10. World Health Organization. WHO Framework Convention on Tobacco Control. Geneva, Switzerland: World Health Organization; 2005. http://www.who.int/tobacco/ framework/WHO_FCTC_english.pdf. Accessed March $6,2019$.

11. World Health Organization. WHO Report on the Global Tobacco Epidemic, 2008: the MPOWER package. Geneva, Switzerland: World Health Organization; 2008. http://www.who.int/tobacco/mpower/mpower_report_ full_2008.pdf. Accessed March 6, 2019.

12. Republic of Philippines, Department of Health. Sin Tax Reform Law of 2012, Republic Act No. 10351. http:// www.doh.gov.ph/Policies-and-Laws/RA10351. Accessed March 6, 2019.

13. Republic of the Philippines, Department of Finance, Taxform. Republic Act No. 11346 (Tobacco Tax Law 2019). https://taxreform.dof.gov.ph/bills/republic-actno-11346-tobacco-tax-law-2019/. Accessed August 2, 2019.

14. Centers for Disease Control and Prevention. Global Youth Tobacco Survey (GYTS) - Overview. https:// nccd.cdc.gov/GTSSDataSurveyResources/Ancillary/ Documentation.aspx?SUID =1\&DOCT $=1$. Accessed April 8, 2019.

15. World Health Organization, Centers for Disease Control and Prevention. Global Youth Tobacco Survey Fact Sheet: Phillipines 2015. Philippines: World Health Organization Western Pacific Region; 2015. https://www.doh.gov.ph/sites/default/files/ publications/2015GYTSFinalFactSheet_1.pdf. Accessed March 20, 2019.

16. World Health Organization. WHO report on the global tobacco epidemic, 2015: raising taxes on tobacco. Geneva, Switzerland: World Health Organization; 2015. https://apps.who.int/iris/bitstream/ handle/10665/178574/9789240694606_eng. pdf?sequence=1. Accessed March 6, 2019.

17. U.S. Department of Health and Human Services. The Health Consequences of Smoking: 50 Years of Progress. A Report of the Surgeon General. Atlanta, GA: U.S. Department of Health and Human Services, Centers for Disease Control and Prevention, National Center for Chronic Disease Prevention and Health Promotion, Office on Smoking and Health; 2014. https://www.ncbi.nlm.nih. gov/books/NBK179276/pdf/Bookshelf_NBK179276. pdf. Accessed March 6, 2019.

18. World Health Organization. Effectiveness of tax and price policies for tobacco control. IARC Handbooks of Cancer Prevention. 2011;18. https://publications.iarc. 
fr/Book-And-Report-Series/Iarc-Handbooks-Of-CancerPrevention/Effectiveness-Of-Tax-And-Price-Policies-ForTobacco-Control-2011. Accessed April 1, 2019.

\section{ACKNOWLEDGEMENTS}

The authors would like to acknowledge Florante Trinidad, from the Tobacco Free Initiative and Mental Health, World Health Organization, Office of the Representative in the Philippines, Manila, Philippines. The findings and conclusions in this report are those of the authors and do not necessarily represent the official position of the U.S. Centers for Disease Control and Prevention.

\section{CONFLICTS OF INTEREST}

The authors have completed and submitted the ICMJE Form for Disclosure of Potential Conflicts of Interest and none was reported.

\section{FUNDING}

Andrew B. Seidenberg is supported by the National Institute on Drug Abuse of the National Institutes of Health under Award Number F31DA045424. All other authors have not declared a specific grant for this research from any funding agency in the public, commercial, or not-for-profit sectors.

\section{AUTHORS' CONTRIBUTIONS}

All authors have substantially contributed to the conception of the work, interpretation of data for the work and drafting and critical revisions of the work for important intellectual content; they have approved the final version for publication and agreed to be accountable for all aspects of the work in ensuring that questions related to the accuracy or integrity of any part of the work are appropriately investigated and resolved. RAA and LMD were responsible for the statistical analysis. RAA analyzed the data and has full responsibility for the work and decision to publish.

PROVENANCE AND PEER REVIEW

Not commissioned; externally peer reviewed. 